INFO ARTIKEL

Riwayat Artikel:

Diterima : 01 Januari 2020

Disetujui : 12 Februari 2020

\title{
GEOGRAFI
}

\section{ANALISIS PENYEBAB ANAK PUTUS SEKOLAH DI DESA SRI AGUNG KECAMATAN BANYUASIN II DITINJAU SECARA GEOGRAFIS}

\author{
Nayla Baningsih ${ }^{1}$, Nuranisa $^{2}$, Dessy Wardiah $^{3}$ \\ ${ }^{1-2}$ Program Studi Pendidikan Geografi, Universitas PGRI Palembang \\ 3 Program Studi Pendidikan Bahasa dan Sastra Indonesia, Universitas PGRI Palembang \\ (区) naylabaningsih215@gmail.com ${ }^{1}$
}

\begin{abstract}
ABSTRAK
Desa Sri Agung Kecamatan Banyuasin II, merupakan daerah dengan potensi yang besar khususnya bidang pertain, tetapi potensi yang dimiliki tersebut tidak sejalan dengan angka pendidikan masyarakatnya. Tujuan penelitian ini adalah untuk mengetahui kondisi ekonomi, motivasi, aksesibilitas wilayah, dan pendidikan orang tua masyarakat Desa Sri Agung. Metode penelitian yang digunakan dalam penelitian ini adalah metode deskriptif kualitatif. Teknik pengumpulan data menggunakan teknik observasi, wawancara dan dokumentasi. Teknik analisis data menggunakan analisis deskritif kualitatif. Hasil penelitian ini menunjukan kondisi perekonomian pendapatan orang tua anak yang putus sekolah diatas Rp 500.000 perbulan berjumlah 6 orang, dan pendapatan responden diatas Rp 1.000 .000 perbulan yaitu ada 9 orang, serta diatas Rp 2.000 .000 perbulan 1 orang. Aksesibilitas wilayah untuk jarak tempuh menujuh sekolah dari SD, SMP dan SMA, jarak tempuh menuju sekolah SD sekitar 9.000 Km sampai 1 $\mathrm{Km}$ paling jauh, untuk jarak tempuh kesekolah SMP sekitar $1 \mathrm{Km}$ sampai 2,5 Km dan untuk SMA jarak tempuhnya sekitar $1 \mathrm{Km}$ sampai 3,6 Km. Alat transpotasi yang digunakan untuk menuju sekolah yaitu sepeda, sepeda motor, dan dengan berjalan kaki ketika musim hujan karena tidak memungkinkan untuk berkendara saat hujan mengingat jalan yang licin dan belum di aspal. Motivasi orang tua terhadap Pendidikan masih rendah, hal ini berpengaruh terhadap pendidikan anak-anak di Desa Sri Agung, karena orang tua lebih memilih untuk menabung dan membelikan sawah ketimbang harus membiayai sekolah anaknya, karena mereka beranggapan bahwa uang tabungannya dapat digunakan untuk membeli sawah untuk diolah sebagai bekal kelangsungan hidup dimasa depan. Tingkat pendidikan orang tua Desa Sri Agung juga termasuk dalam kategori rendah rata-rata hanya sampai disekolah menengah, sehingga tingkat kesadaran akan pentingnya pendidikan berkurang, hingga menyebabkan anak-anak di Desa Sri Agung banyak yang putus sekolah.
\end{abstract}

Kata Kunci: Anak Putus Sekolah, Aksesbilitas Wilayah, Pendidikan Orang Tua

\section{PENDAHULUAN}

Pendidikan yaitu hak yang fundamental dan wajib untuk dipenuhi dengan kerjasama dari orang tua, masyarakat dan pemerintah di atur dalam Undang-Undang Pendidikan No. 20 Tahun 2003 tentang Sistem Pendidikan Nasional pasal 34 ayat 1-3 telah ditetapkan bahwa:

1. Warga negara yang berusia 6 tahun dapat mengikuti wajib belajar.
2. Setiap Pemerintah daerah menjamin terselenggaranya wajib belajar minimal pada jejang pendidikan dasar tanpa memungut biaya.

3. Wajib belajar merupakan tanggung jawab negara yang diselenggarakan oleh lembaga pendidikan, pemerintah dan masyarakat Mua, (2017: 2).

Pendidikan di Indonesia telah menujukan keberhasilan yang cukup besar. Wajib belajar 9 
tahun yang didukung pembangunan insfratruktur dan diteruskan dengan wajib belajar 9 tahun adalah program sektor pendidikan yang diakui cukup sukses. Kasus tinggal kelas, terlambat masuk sekolah, anak putus sekolah dan tidak mampuan untuk meneruskan sekolah kejenjang yang lebih tinggi merupakan hal yang cukup banyak di dunia pendidikan Kamsihyati, (2016:17). Selain itu, berpendidikan rendah dan tidak menutaskan wajib belajar 9 Tahun sesuai dengan program pemerintah di dalam sistem pendidikan nasional UU 20 Tahun 2003 telah jelas disebutkan bahwa setiap warga negara yang berusia 15 Tahun wajib wajib mengikuti jenjang pendidikan dasar, dengan pendidikan kita dapat meningkatkan kualitas sumber daya manusia yang dapat mendukung pembangunan pada masyarakat, contohnya permasalahan pendidikan yang dihadapi pemerintah adalah tingginya anak yang tidak melanjutkan sekolah menurut Bagoe, (2015:3) menyatakan jenis putus sekolah dapat dikelompokan menjadi 3 yaitu putus sekolah atau berhenti dalam jenjang, putus sekolah di ujung jenjang atau berhenti antara jenjang

Putus sekolah secara umum dapat diartikan sebagai orang atau anak yang keluar dalam suatu sistem pendidikan sebelum mereka menamatkan pendidikan sesuai dengan jenjang waktu sistem persekolahan yang dikuti. Dengan demikian putus sekolah dapat pula diartikan tidak tamat atau gagal dalam belajar ketingkat lanjut Bagoe, (2015:3). Salah satunya terdapat anak yang putus sekolah di Desa Sri Agung Kecamatan Banyuasin II, dilihat dari perekonomian keluarga juga sangat penting dalam menempuh pendidikan. Pendapatan perekonomian yang rendah dapat dilihat dari sisi keluarga yang hanya berpenghasilan rendah atau pengangguran. Pengangguran di suatu keluarga juga dapat menyebabkan anak putus sekolah karena kurangnya pendapatan, Adanya pengangguran di suatu keluarga karena kurang ilmu pengetahuan dan wawasan dalam keluarga.

Untuk penghasilan ekonomi masyarakat Desa Sri Agung mayoritas masyarakat penghasil petani padi yang hanya menanam satu musim sekali, pertanian disana terpatok pada musim penghujan, karena pada musim kemarau mereka akan kesulitan untuk menanam padi, karena kondisi air disana asin pada musim kemarau, sehingga tidak memungkinkan untuk melakukan cocok tanam. Dengan kondisi perekonomian yang tidak stabil sehingga masyarakat tidak terlalu memikiran akan pentingnya pendidikan, ini dapat dilihat dari jumlah sekolahan yang ada di desa tersebut yang mana hanya terdapat 1 PAUD, 2 TK, dan 1 SD. Sedangkan untuk jenjang pendidikan sekolah yang lebih tinggi seperti SMP dan SMA masyarakat desa tersebut harus melanjutkannya di desa seberang (BPS, 2018 Kec. Banyuasin II).

Tujuan penelitian untuk mengetahui kondisi ekonomi orang tua, motivasi anak, aksesibilitas wilayah, serta pendidikan orang tua yang penyebab anak putus sekolah pada tingkat pendidikan SD, SMP dan SMA di Desa Sri Agung Kecamatan Banyuasin II tahun 20182019. Anak putus sekolah adalah masalah yang sangat menarik untuk dikaji karena menyakut permasalahan dalam yang sering kita temui dikehidupan masyarakat khusunya masyarakat pedesaan yang banyak berfikir secara primitif dan tidak maju menyesuaikan zaman sekarang atau modern.

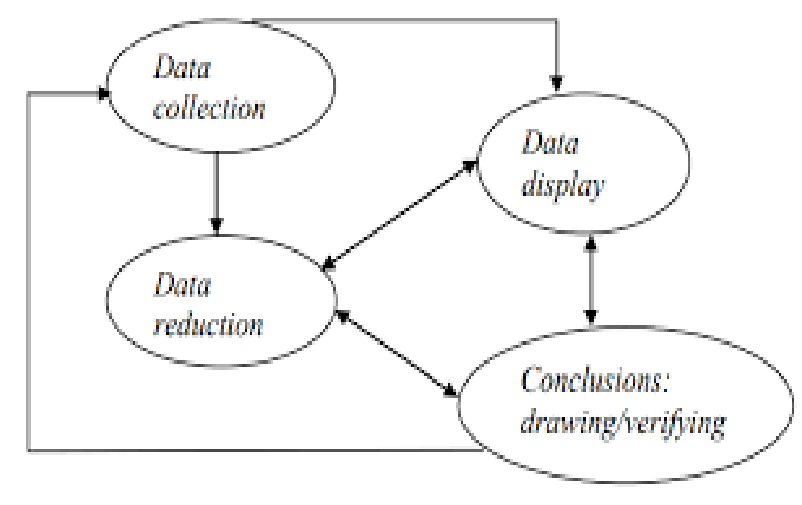

\section{METODOLOGI PENELITIAN}

Penelitian dilakukan di Desa Sri Agung Kecamatan Banyuasin II. Penyebab anak putus sekolah dilatarbelakangi oleh faktor internal dan eksternal. Analisis data dilakukan menggunakan metode deskriptif kualitatif. Analisis kualitatif adalah sebuah metode penelitian yang berlandaskan untuk meneliti pada kondisi objek yang alamiah dimana peneliti sendiri yang menjadi intrumen kunci, pengolahan data dengan trianggulasi (gabungan) Sugiyono (2017:15). Untuk informan kunci orang tua dan kepala desa sedangkan informan umum anak yang putus sekolah yang terlibat langsung dalam peneliti.

Sumber data penelitian yang digunakan adalah data Primer dan data sekunder. Data primer adalah data yang diperoleh secara langsung dan langsung dari objek yang diteliti oleh peneliti kepada responden, sedangkan data sekunder adalah data dari hasil pengumpulan orang atau instansi 
lain dalam bentuk publikasi yang di peroleh melalui BPS (Badan pusat Statistik), dan jurnal jurnal.

Teknik Pengumpulan data yang digunakan dalam penelitian antara lain Observasi, Wawancara, Dokumentasi. Observasi adalah salah satu cara pengumpulan data dengan melihat atau terjun langsung kelapangan. Wawancara merupakan pengumpulan data dengan cara membuat sederet pertanyan kepada narasumber melaui percakapan langsung. Dokumentasi adalah suatu metode mencari data mengenai halhal atau variabel yang berubah catatan, transkip, buku, surat kabar, notulen, dan sebagainya Arikunto, (2010:274).

Teknik Triangulasi sebagai pengecekan data dari berbagai sumber dengan berbagai cara, dan berbagai waktu. Sumber triangulasi terdapat teknik pengumpulan data dan waktu Sugiyono, (2010: 273).

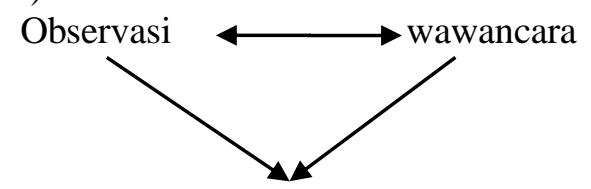

Dokumentasi

Gambar 1. Teknik Triangulasi "Sumber" Pengumpulan data (Sumber:Sugiyono, 2010: 273).

Gambar 2. Komponen Dalam Analisis Data (Interactive Model)

\section{HASIL DAN PEMBAHASAN}

Kabupaten Banyuasin mempunyai wilayah seluas $11.832,99 \mathrm{Km} 2$ dan terbagai menjadi 19 kecamatan diantaranya yaitu Kecamatan Banyuasin II dengan wilayah yang seluas 3.632,4 $\mathrm{Km} 2$ atau sekitar 30,70 \% dari luas Kabupaten Banyuasin. Letak Geografis Kabupaten Banyuasin terletak pada posisi $1,30^{\circ}-4,0^{\circ}$-Lintang Selatan dan $104^{0}-00^{\prime}-105^{0}-35^{\prime}$ Bujur Timur. Secara geografis Kabupaten Banyuasin berbatasan dengan:

- Sebelah Utara berbatasan dengan Provinsi Jambi, Kabupaten Musi Banyuasin, dan Selat Bangka.

- Di sebelah Selatan berbatasan dengan Kabupaten Muara Enim, Kabupaten Ogan komering ilir, dan Kota Palembang.

- Kabupaten Musi Banyuasin berada di batasan sebelah Barat
- Sebelah Timur berbatasan dengan Selat Bangka dan Kabupaten Ogan komering ulu.

Penyebab anak putus sekolah di desa Sri Agung disebabkan adanya faktor internal dan eksternal.

\section{a. Faktor Internal}

Merupakan faktor yang berasal dari dalam diri anak dan kemampuan belajar yang menjadi faktor-faktor tersebut antara lain ekonomi dan motivasi dapat menyebabkan rendahnya minat anak serta fasilitas belajar dan perhatian orang tua yang kurang. Permasalahan yang menyebabkan anak mengalami putus sekolah yaitu:

1. Ekonomi

Ekonomi merupakan pengetahuan mengenai asas-asas penghasilan, produksi, distribusi, pembasaran dan pemakaian barang serta kekayaan penghematan, menjalakan usaha menurut ajaran ekonomi KLBIM, Ali (2006:89). Kondisi ekonomi Desa Sri Agung tidak tentu dalam sebulan misalnya dari pendapatan bersih orang tua dari pekerjaan atau tingkat pendapatan sangat berkaitan apabila jenis pekerjaan orang tua yang layak maka pendapatan yang di peroleh akan tinggi, sebalikanya apa bila jenis pekerjaan dan tingkat pendapatan yang rendah akan mempengaruhi dalam pemenuhan fasilitas pendidikan sehingga kesulitan biaya pendidikan yang cukup tinggi dan jumlah beban keluarga kecil akan berbeda dengan jumlah keluarga yang besar yang di maksud disini adalah jumlah anggota keluarga yang masih menjadi beban tanggungan atau belum bekerja.

Untuk masyarakat desa Sri Agung mayoritas masyarkatnya penghasil padi. Dari keluarga keempat tersebut mempunyai hubungan yang erat terhadap pindidikan anak serta perhatian orang tua terhadap penyedian perlengkapan dan sarana belajar, meja dan kursi belajar serta kurangnya perhatian orang tua yang kurang terhadap penyediaan perlengkapan dan sarana belajar akan membuat anak malas untuk belajar sehingga dalam sekolahnya anak akan malas untuk belajar sehingga dalam belajar anak akan banyak mengalami kesulitan dan tidak mendapatkan prestasi yang baik akhirnya memilih untuk putus sekolah Kamsihyati, (2016:20).

\section{Motivasi}

Motivasi menurut Djaali dan Sumadi (2017:101-102) adalah keadaan yang terdapat dalam diri seorang yang mendorongnya untuk melakukan aktivitas tertentu guna pencapaian satu tujuan. Motivasi adalah proses membangkitkan, mengarahkan, dan memantapkan perilaku arah suatu tujuhan. Dari tiga definisi tersebut yang 
terdapat dalam diri seorang yang mendorongnya untuk melakukan aktivtitas tertentu guna mencapai suatu tujuan (kebutuhan). motivasi juga mempengaruhi misalnya motivasi orang tua yang rendah karena orang tua lebih memilih untuk menabung dengan membelikan sawah serta hewan ternak dan beranggapan uang tabungannya dapat digunakan untuk membeli sawah dan rendahnya minat anak dapat disebabkan oleh perhatian orang tua yang kurang.

\section{b. Faktor Eksternal}

Faktor yang berasal dari luar diri anak putus sekolah baik berasal dari orang tua yakni keadaan ekonomi keluarga, perhatian orang tua, hubungan orang tua yang kurang harmonis, latar belakang pendidikan orang tua sehingga menyebabkan dorongan anak untuk bersekolah juga rendah atau pun lingkungan yang kurang mendukung seperti jarak rumah dengan sekolah yang jauh.

Adapun faktor yang mempengaruhi penyebeb anak putus sekolah sebagai berikut:

1. Aksesibilitas Wilayah

Aksesibilitas Wilayah penyebab anak putus sekolah dari jarak dari rumah kesekolah yang jauh. Dalam penelitian ini Aksesibilitas Wilayah berati mudah atau tidaknya dijangkau dari rumah responden, meliputi: 1) Jarak, jarak dapat dibeda menjadi dua menjadi dua yaitu: (a) jarak tempuh: jarak tempuh oleh anak menuju ke sekolah yang di ukur dari rumah responden, dengan satu kilometer; (b) waktu tempuh: waktu tempuh merupakan lamanya waktu yang harus di tempuh oleh anak menuju ke sekolah yang diukur dari responden dengan satuan menit; 2) Alat Transpotasi yang digunakan: untuk menuju ke sekolah dapat berupa kendaran pribadi maupun kendaran umum; 3) Biaya Transpotasi: biaya yang harus dikeluarkan siswa untuk menuju ke sekolah dan untuk pulang sekolah ke tempat tinggal mereka; 4) Fasilitas Jalan: kondisi jalan

\section{Pendidikan Orang Tua}

Tingkat pendidikan orang tua di desa Sri Agung masih sangat rendah sehingga melatar belakangi pendidikan anak. Semakin tinggi tingkat pendidikan orang tua maka cara pola berpikir tentang pentingnya pendidikan anak hingga jenjang pendidikan yang lebih tinggi dari orang tuanya. Sebaliknya juga apabila tingkat pendidikan orang tua rendah maka akan berpengaruh pola pikir orang tua terhadap pentingnya pendidikan sehingga mereka berpikir bahwa pendidikan tidaklah terlalu penting sehingga keinginan menyekolahkan anak hingga jenjang lebih tinggi sangatlah rendah Aristin, (2015:34). Berdasarkan dari hasil penelitian menujukan tingkat pendidikan orang tua di Desa Sri Agung, dari tidak tamat SD 3 orang tua, sedangkan untuk tingkat SMP pendidikan orang tua ada 2 orang tua.

Responden yang berpendapatan Rp. 1.000.000 sampai Rp 2.000.000 dalam perbulan.

Tabel 1. Pendapatan responden 1 jt-2jt/bln

\begin{tabular}{lll}
\hline $\begin{array}{l}\text { Nama } \\
\text { Responden }\end{array}$ & $\begin{array}{l}\text { Pendapatan } \\
\text { perbulan }\end{array}$ & $\begin{array}{l}\text { Pengeluaran } \\
\text { perbulan }\end{array}$ \\
\hline Poniman & Rp. 1.000 .000 & Rp. 800.000 \\
Tutur & Rp. 1.000 .000 & Rp. 800.000 \\
Sulaiman & Rp. 1.500 .000 & Rp. 1.000 .000 \\
Rudi & Rp. 1.000 .000 & Rp. 800.000 \\
Simin & Rp 1.500 .000 & Rp. 1.000 .000 \\
Sumeri & Rp. 1.000 .000 & Rp. 800.000 \\
Dulah Rajah & Rp. 1.000 .000 & Rp. 700.000 \\
Candra & Rp. 1.000 .000 & Rp. 800.000 \\
Siswanto & Rp. 1.000 .000 & Rp. 800.000 \\
Parman & Rp. 2000.000 & Rp. 1.000 .000 \\
\hline
\end{tabular}

(Sumber : Analisis Data, 2019)

Responden yang berpendapatan Rp. 500.000 sampai Rp. 800.000 dalam perbulan.

Tabel 2. pendapatan 500rb-800rb/bln

\begin{tabular}{lcc}
\hline $\begin{array}{l}\text { Nama } \\
\text { responden }\end{array}$ & $\begin{array}{c}\text { Pendapatan } \\
\text { perbulan }\end{array}$ & $\begin{array}{c}\text { Pengeluaran } \\
\text { perbulan }\end{array}$ \\
\hline Mahruri & Rp. 500.000 & Rp. 400.000 \\
Sakim & Rp. 600.000 & Rp. 400.000 \\
Sandi Banjir & Rp. 600.000 & Rp. 500.000 \\
Mad Yasir & Rp. 600.000 & Rp. 500.000 \\
Mardasiman & Rp. 800.000 & Rp. 600.000 \\
Cahyono & Rp. 800.000 & Rp. 600.000 \\
\hline
\end{tabular}

(Sumber : Analisis Data, 2019)

Penyebab anak putus sekolah di desa Sri Agung dari faktor ekonomi, aksesibilitas, motivasi dan pendidikan orang tua. Hasil penelitian ini didukung oleh pendapat Wassahua, (2016:99) bahwa penyebab anak putus sekolah antara lainnya faktor internal dan eksternal. Untuk faktor internal sendiri yaitu ekonomi dan motivasi sedangkan faktor eksternal yaitu aksesibilitas dan pendidikan orang tua.

Untuk ekonomi keluarga di Desa Sri Agung tidak tentu dalam sebulan karena penghasilan perekonomian di Desa Sri Agung mayoritas masyarakat berpenghasilan petani padi yang hanya menanam satu musim sekali. Hasil penelitian ini juga didukung oleh pendapat Aristin, (2015:33) menyatakan kondisi ekonomi suatu keluarga sangat berpengaruh dalam kehidupan sehari-hari khusunya dalam menentukan perkembangan 
pendidikan anak seperti dalam kondisi ekonomi dalam penelitian ini meliputi tingkat pendidikan, jenis pekerjaan, tingkat pendapatan, jumlah tanggungan keluarga kempat tersebut mempunyai hubungan yang erat terhadap pendidikan anak.

Motivasi anak ada 2 yaitu motivasi dari dalam, dan motivasi dari luar, untuk motivasi dalam yaitu diri anak sendiri motivasi dari luar yaitu orang tua, sedangkan motivasi orang tua, di Desa Sri Agung sangat rendah karena orang tua lebih memilih untuk menabung dengan membelikan sawah serta hewan ternak dan beranggapan uang tabungannya dapat digunakan untuk membeli sawah dan rendahnya minat anak dapat disebabkan oleh perhatian orang tua yang kurang. Hasil penelitian ini didukung oleh Sutiasnah (2015:10) menyatakan motivasi yang kurang diberikan orang tua menyebabkan anakanak mereka putus sekolah seperti kurangnya perhatian orang tua mereka membuat mereka malas untuk sekolah, hura-hura dengan keluyuran tidak tahu kemana arahnya atau tidak ada manfaatnya. Aksesibilitas wilayah meliputi (1) jarak tempuh untuk menujuh sekolah dari SD, SMP dan SMA. Untuk jarak tempuh menuju sekolah SD sekitar $9.000 \mathrm{Km}$ sampai $1 \mathrm{Km}$ paling jauh dan sedangkan untuk jarak ke SMP sekitar 1 $\mathrm{Km}$ sampai 2,5 $\mathrm{Km}$ dan untuk SMA jarak tempuhnya sekitar $1 \mathrm{Km}$ sampai 3,6 Km dan yang (2) alat transpotasi yang di gunakan untuk yaitu sepeda, sepeda motor, dan bahan jalan kaki jika musim hujan dan (3) sarana dan prasarana jalan masih tanah, jika musim hujan kondisi jalan sangat susah sehingga kondisi jalan seperti itu menyebabkan anak putus sekolah, selain itu juga tempat sekolahnya jauh, sedangkan untuk fasilitas transpotasi disana juga tidak mendukung misalnya tidak ada transpotasi umum seperti angkot mau grab hingga kondisi seperti itu membuat anak malas bersekolah.Pendidikan orang tua, di Desa Sri Agung pendidikan orang tua anak yang putus sekolah mayoritas pendidikannya SD bahkan ada yang tidak lulus SD. Untuk jumlah sekolah yang ada di Desa Sri Agung terdapat 1 PAUD, 2 TK dan 1 SD (BPS,2018 Kec. Banyuasin II). Berdasarkan dari hasil penelitian menunjukkan tingkat pendidikan orang tua di Desa Sri Agung, dari tidak tamat SD 3 orang tua, sedangkan untuk tingkat SMP pendidikan orang tua ada 2 orang tua.

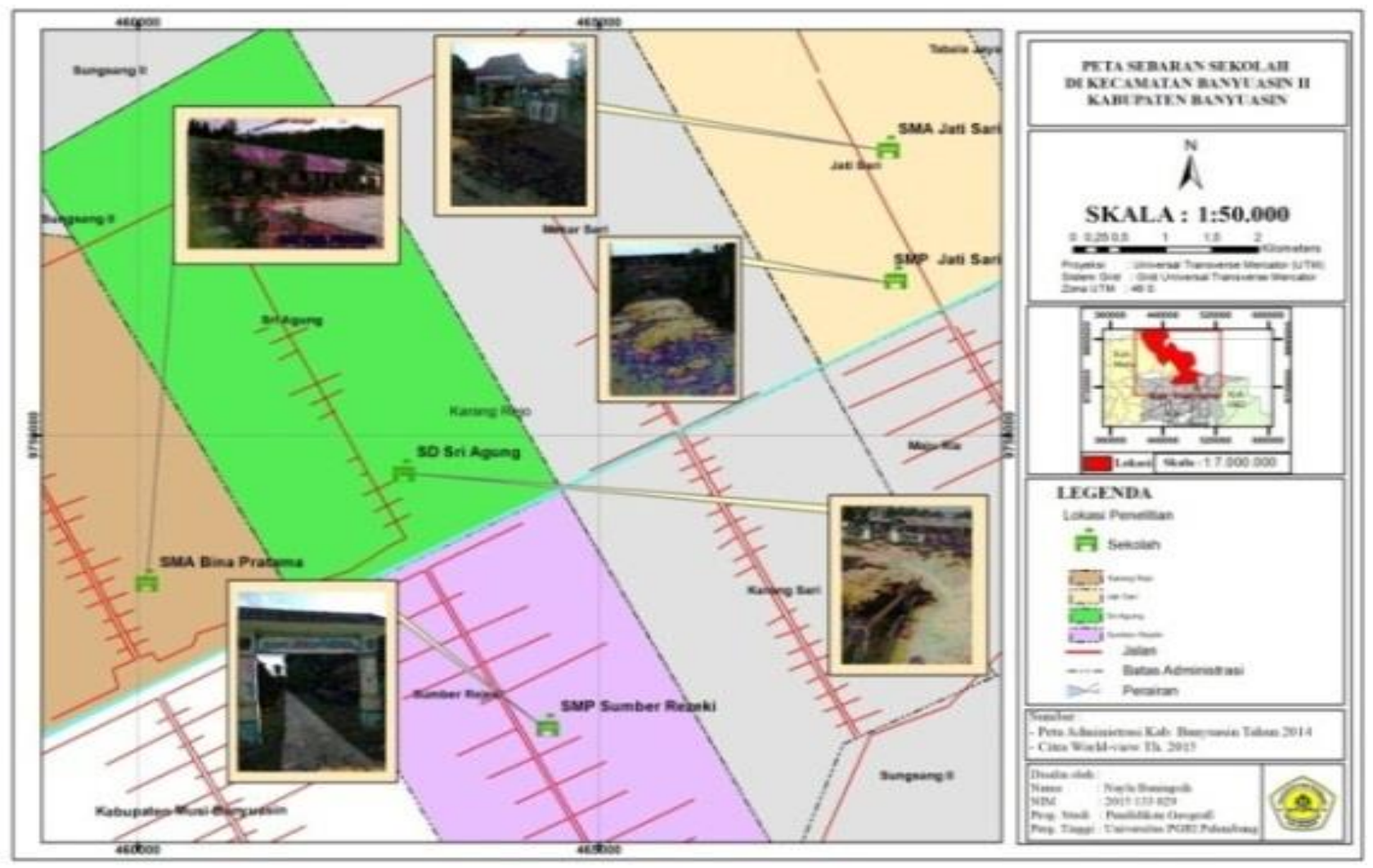

Gambar 3. Peta Persebaran Sekolah 


\section{SIMPULAN}

Dari hasil penelitian maka dapat disimpulkan bawah penyebab anak putus sekolah di Desa Sri Agung dikarenakan Kondisi ekonomi orang tua, motivasi anak, Kondisi Aksesibilitas Wilayah serta pendidikan orang tua. Dari Kondisi ekonomi orang tua tidak tentu dalam sebulan dan jenis pekerjaannya sedangkan motivasi anak yaitu motivasi dari luar dan motivasi dalam, untuk motivasi dari luar yaitu orang tua serta kondisi aksesibilitas wilayah jarak dari rumah untuk menuju sekolah yang jauh sedangkan untuk aksesibilitas untuk menuju sekolah dapat dilihat dari jarak tempuh, waktu tempuh, ketersedian alat transpotasi, biaya atau ongkos untuk menuju sekolah serta sarana dan prasarana jalan menujukan kondisi yang kurang baik dan yang terakhir Pendidikan orang tua mayoritas pendidikan orang tuanya SD bahkan ada yang tidak lulus SD. Kempat hal tersebut sangat berpengaruhi penyebab anak putus sekolah.

Disarankan agar pemerintah perlu mengadakan sosialisasi dalam meningkatkan kesadaran masyarakat tentang pendidikan, tentunya dengan mengikuti sertakan tokoh masyarakat desa tersebut mengenai pentingnya pendidikan sehingga masyarakat desa Sri Agung.

\section{DAFTAR PUSTAKA}

Ali, Muhammad. (2006). Kamus Lengkap Bahasa Indonesia Moderen. Jakarta: Puataka Amani.

Aristin, Nevy Farista. (2015). Faktor-Faktor Yang Berpengaruh Terhadap Anak Putus Sekolah Tingkat Sekolah Menengah Pertama (SMP) DI Kecamatan Bondowos. Universitas Lambung Mangkurat
Arikunto, Suharsimi. (2010). Prsedur Penelitian Suatu Pendekatan Praktik. Jakarta: Rineka Cipta.

Bagoe, Rizal. (2015). Faktor yang pengaruhi penyebab Anak Putus Sekolah Di Desa Suka Damai Kecamatan Bulango Utara Kabupaten Bone Bolango. Universitas Negeri Gorontalo.

BPS. (2018). Badan Pusat Statistik 2018 .BPS Kabupaten Banyuasin: BPS-Statistics of Banyuasin Regency

Djaali \& Sumadi. (2017). Psikologi Pendidikan. Jakarta: Bumi Aksara.

Kamsihyati, Titik. (2016). Kajian Faktor Penyebab Anak Putus Sekolah Di Desa Jangrana Kecamatan Kesugihan Kabupaten Cilacap. Universitas Muhammadiyah Purwokerto.

Mua, Vinny Briggita. (2017). Penyebab anak Putus Sekolah Dari Anak Petani Dan NonPetani Di Desa Sea Dan Desa Warembungan Kecamatan Pineleng Kabupaten Minahasa. Agri-Sosial Ekonomi Unsart.

Sugiyono. (2010). Metode Penelitian Kuantitatif, Kualitatif, dan $R \& D$. Bandung: Alfabeta.

(2017). Metode Penelitian Kuantitatif, Kualitatif, dan $R \& D$. Bandung: Alfabeta.

Sutiasnah, Resi Anggun. (2015). Faktor-Faktor Penyebab Anak Putus Sekolah. Universitas Riau.

Wassahua, Sarfa. (2016). Faktor Penyebab Putus Sekolah Di Kampung Wara Negara Hative Kecil Kota Ambon. 